\title{
Influence of culture media on the physical and chemical properties of $\mathrm{Ag}-\mathrm{TiCN}$ coatings
}

\author{
I Carvalho ${ }^{1,2}$, R Escobar Galindo ${ }^{3}$, M Henriques ${ }^{2}$, C Palacio $^{4}$ \\ and S Carvalho ${ }^{1,5}$ \\ ${ }^{1}$ GRF-CFUM, University of Minho, Campus of Azurém, 4800-058 Guimarães, Portugal \\ ${ }^{2} \mathrm{CEB}$, Centre for Biological Engineering, LIBRO-Laboratório de Insvestigação em Biofilmes Rosário \\ Oliveira, University of Minho, Campus of Gualtar, 4700-057 Braga, Portugal \\ ${ }^{3}$ Instituto de Ciencia de Materiales de Madrid (ICMM-CSIC), Cantoblanco, Spain \\ ${ }^{4}$ Departamento de Física Aplicada, Universidad Autonoma de Madrid, Cantoblanco, Spain \\ ${ }^{5}$ SEG-CEMUC Mechanical Engineering Department, University of Coimbra, 3030-788 \\ Coimbra, Portugal \\ E-mail: isascarvalho@hotmail.com
}

Received 8 April 2014, revised 16 June 2014

Accepted for publication 24 June 2014

Published 18 July 2014

\begin{abstract}
The aim of this study was to verify the possible physical and chemical changes that may occur on the surface of $\mathrm{Ag}-\mathrm{TiCN}$ coatings after exposure to the culture media used in microbiological and cytotoxic assays, respectively tryptic soy broth (TSB) and Dulbecco's modified eagle's medium (DMEM). After sample immersion for $24 \mathrm{~h}$ in the media, analyses were performed by glow discharge optical emission spectroscopy discharge radiation (GDOES), Rutherford backscattering spectroscopy (RBS) and x-ray photoelectron spectroscopy (XPS). The results of GDOES profile, RBS and XPS spectra, of samples immersed in TSB, demonstrated the formation of a thin layer of carbon, oxygen and nitrogen that could be due to the presence of proteins in TSB. After $24 \mathrm{~h}$ of immersion in DMEM, the results showed the formation of a thin layer of calcium phosphates on the surface, since the coatings displayed a highly oxidized surface in which calcium and phosphorus were detected. All these results suggested that the formation of a layer on the coating surface prevented the release of silver ions in concentrations that allow antibacterial activity.
\end{abstract}

Keywords: Ag coatings, microbial and cell culture media, GDOES, RBS, XPS

(Some figures may appear in colour only in the online journal)

\section{Introduction}

Stainless steel AISI 316L (SS 316L), cobalt-chromium alloys and titanium and its alloys are the materials most commonly used in the development of medical devices [1,2]. They are used in orthopaedics in implant surgery since they present good mechanical properties and, in the case of stainless steel, also low cost [1-3]. However, SS $316 \mathrm{~L}$ is a material susceptible to corrosion when in prolonged contact with body fluids $[3,4]$. To overcome this problem, the surface modification of SS 316L with titanium carbonitride ( $\mathrm{TiCN}$ ) coatings, to improve and control the corrosion resistance and biocompatible properties, is a promising process. TiCN presents good mechanical and tribological properties [5], in which wear and fatigue behaviours were extensively studied [5-7]. In the literature, the good corrosion resistance of $\mathrm{TiCN}$ [3] and its noncytotoxic character [8] are also reported, resulting in an interesting material for biomedical applications. Nevertheless, this material does not present any antimicrobial effect and the infection caused by microorganisms is one of the causes of failure of these devices. Hence, surface modification by coatings doped with silver is one of the most used approaches to control the bacterial adhesion and colonization. As silver demonstrates high antimicrobial activity and a relatively 
Table 1. Chemical composition (standard deviation between 0.2 and 0.8 ), deposition parameters (gas flow, $\Phi$, and current density) and thickness of deposited coatings.

\begin{tabular}{|c|c|c|c|c|c|c|c|c|c|c|}
\hline \multirow{2}{*}{$\begin{array}{l}\text { Samples } \\
\text { Ag/Ti }\end{array}$} & \multicolumn{4}{|c|}{ Chemical composition (at\%) } & \multirow{2}{*}{$\begin{array}{l}\Phi \mathrm{N}_{2} \\
(\mathrm{sccm})\end{array}$} & \multirow{2}{*}{$\begin{array}{l}\Phi \mathrm{C}_{2} \mathrm{H}_{2} \\
(\mathrm{sccm})\end{array}$} & \multicolumn{2}{|c|}{ Current density $\left(\mathrm{mA} \mathrm{cm}^{-2}\right)$} & \multirow{2}{*}{$\begin{array}{l}\text { Thickness } \\
(\mu \mathrm{m})\end{array}$} & \multirow{2}{*}{$\begin{array}{l}\text { Deposition } \\
\text { rate }\left(\mu \mathrm{m} \mathrm{h}^{-1}\right)\end{array}$} \\
\hline & $\mathrm{Ti}$ & $\mathrm{C}$ & $\mathrm{N}$ & $\mathrm{Ag}$ & & & $\mathrm{Ti}$ & $\mathrm{Ti}+\mathrm{Ag}$ & & \\
\hline 0 & 37 & 29 & 34 & 0 & 6 & 6 & 10 & 0 & $2.9 \pm 0.1$ & $1.6 \pm 0.1$ \\
\hline 0.20 & 32 & 30 & 32 & 6 & 8.5 & 8 & 10 & 6 & $1.4 \pm 0.2$ & $1.4 \pm 0.2$ \\
\hline
\end{tabular}

low cytotoxicity, it has been the mostly used metal [9-13]. According to a previous study [5], the incorporation of silver into TiCN coatings to be used in implant and medical devices must be limited up to 6 at $\%$ to ensure a good balance between tribological and biocompatibility properties. Some studies revealed that the increase in silver contents not only leads to a better antimicrobial effect, but also shows an increase in the cytotoxicity $[14,15]$. Some researchers who worked with similar coatings of $\mathrm{Ag}-\mathrm{TiCN}$, produced also by physical vapour deposition (PVD), have reported the occurrence of $\mathrm{Ag}^{+}$ ion released after material contact with the simulated body fluid $[14,16,17]$.

In a previous study [18], Ag-TiCN coated SS 316L showed no antibacterial effect, even for relatively large quantities of silver (15 at\%), conflicting with other published results $[9,17,19-23]$. In that study, the silver nanoparticles embedded in the TiCN matrix did not produce any antibacterial effect, since there was no ionization, or it occurred at very low concentrations, and as the antibacterial activity is dependent on the total number of $\mathrm{Ag}^{+}$ions this leads to believe that something prevents its ionization. One explanation for the absence of antibacterial activity may be related to the culture medium used in microbiological assays, tryptic soy broth (TSB), which can somehow influence the release of silver ions. Additionally, in another study [5], the cytotoxicity of coatings with high Ag atomic percentage was tested, using Dulbecco's modified eagle's medium (DMEM) as the culture medium of animal cells, and the results showed no cytotoxic effects. In this case also, the culture medium appears to influence the release of $\mathrm{Ag}^{+}$ ions, and a conclusion drawn is that the high concentration of $\mathrm{Cl}^{-}$anions present in the TBS $\left(5.0 \mathrm{~g} \mathrm{l}^{-1}\right.$ of $\left.\mathrm{NaCl}\right)$ and DMEM $\left(6.4 \mathrm{~g} \mathrm{l}^{-1}\right.$ of $\left.\mathrm{NaCl}\right)$ media promotes an effect on the solubility and concentration of $\mathrm{Ag}^{+}$ions promoting $\mathrm{AgCl}$ precipitation, reducing in this way the antibacterial effect [24]. Accordingly, the aim of this work is to evaluate the possible physical and chemical changes that may occur in the coating surfaces after being exposed to TSB and DMEM. In order to achieve such a goal, advanced surface characterization techniques were used.

\section{Materials and methods}

\subsection{Coating preparation}

Ag-TiCN coatings were deposited by reactive dc magnetron sputtering, using two targets $\left(200 \times 100 \mathrm{~mm}^{2}\right)$ - Ti and Ti+Ag, onto polished and ultrasonically cleaned SS 316L (20 $\times$ $20 \mathrm{~mm}^{2}$ ). In order to introduce silver nanoparticles into the coatings, one Ti target was modified with silver pellets that were glued on the erosion area target with silver paint, maintaining a Ti/Ag area ratio on this target of around 6.7, corresponding to a relative $\mathrm{Ag}$ sputtering area of $15 \%$. The depositions were carried out in $\mathrm{Ar}, \mathrm{C}_{2} \mathrm{H}_{2}$ and $\mathrm{N}_{2}$ atmospheres. The substrates were spaced $70 \mathrm{~mm}$ from the targets and were rotated at a constant speed of $7 \mathrm{rpm}$. The films were grown at a constant temperature $(573 \mathrm{~K})$ and bias voltage $(-70 \mathrm{~V})$. Argon flow was kept constant at $60 \mathrm{sccm}$ while the reactive gas fluxes $\left(\mathrm{C}_{2} \mathrm{H}_{2}\right.$ and $\left.\mathrm{N}_{2}\right)$ were changed in the ranges $6-8 \mathrm{sccm}$ and $6-8.5 \mathrm{sccm}$, respectively, in order not to change the $\mathrm{C}$ and $\mathrm{N}$ contents significantly. The base pressure in the deposition chamber was about $10^{-3} \mathrm{~Pa}$ and rose up to values around $10^{-1} \mathrm{~Pa}$ during the depositions. The current density applied to each magnetron was adjusted in order to obtain two different $\mathrm{Ag} / \mathrm{Ti}$ atomic ratios, with $\mathrm{Ag}$ content of 0 and 6 at $\%$. Further details about the synthesis conditions can be found elsewhere [25].

TiCN coatings with and without silver (previously sterilized at $121^{\circ} \mathrm{C}$ for $15 \mathrm{~min}$ ) were immersed into $3 \mathrm{ml}$ of TSB (Sigma) or DMEM (Sigma) for $24 \mathrm{~h}$, at $37^{\circ} \mathrm{C}$ under a constant agitation of $120 \mathrm{rpm}$. Then the supernatants were removed, the coatings were rinsed with Milli-Q water and placed in a sealed desiccator. Afterwards, the coating surface was evaluated by several techniques (described below) to observe the changes promoted by the exposure to media culture.

\subsection{Chemical and physical analysis}

The chemical composition of the deposited films was measured by electron probe microanalysis (EPMA) using a Cameca SX 50 apparatus.

The film thickness was calculated from the diameters of the rings by ball cratering tests. The deposition rate was calculated to control the growth of films. All parameters used were based on previous work that had a clear objective: to obtain a seemingly great composition, not compromising the tribological and mechanical part [5, 26].

Glow discharge optical emission spectroscopy (GDOES) and Rutherford backscattering spectrometry (RBS) were performed in order to detect small variations in the composition of the coating surface and in the elementary distribution in depth, with particular focus on the distribution of silver after 0 and $24 \mathrm{~h}$ of immersion. GDOES experiments were performed using a Jobin Yvon RF GD profiler equipped with a $4 \mathrm{~mm}$ diameter anode and operating at a typical radio frequency discharge pressure of $650 \mathrm{~Pa}$ and a power of $40 \mathrm{~W}$. RBS experiments were performed using $3.7 \mathrm{MeV} \mathrm{He}^{+}$at an ion dose of $10 \mu \mathrm{C}$. The data were acquired simultaneously with two silicon surface barrier detectors located at scattering angles of $170^{\circ}$ and $135^{\circ}$, with an energy resolution of $16 \mathrm{keV}$. RBS spectra were fitted with the software program RBX [27]. 

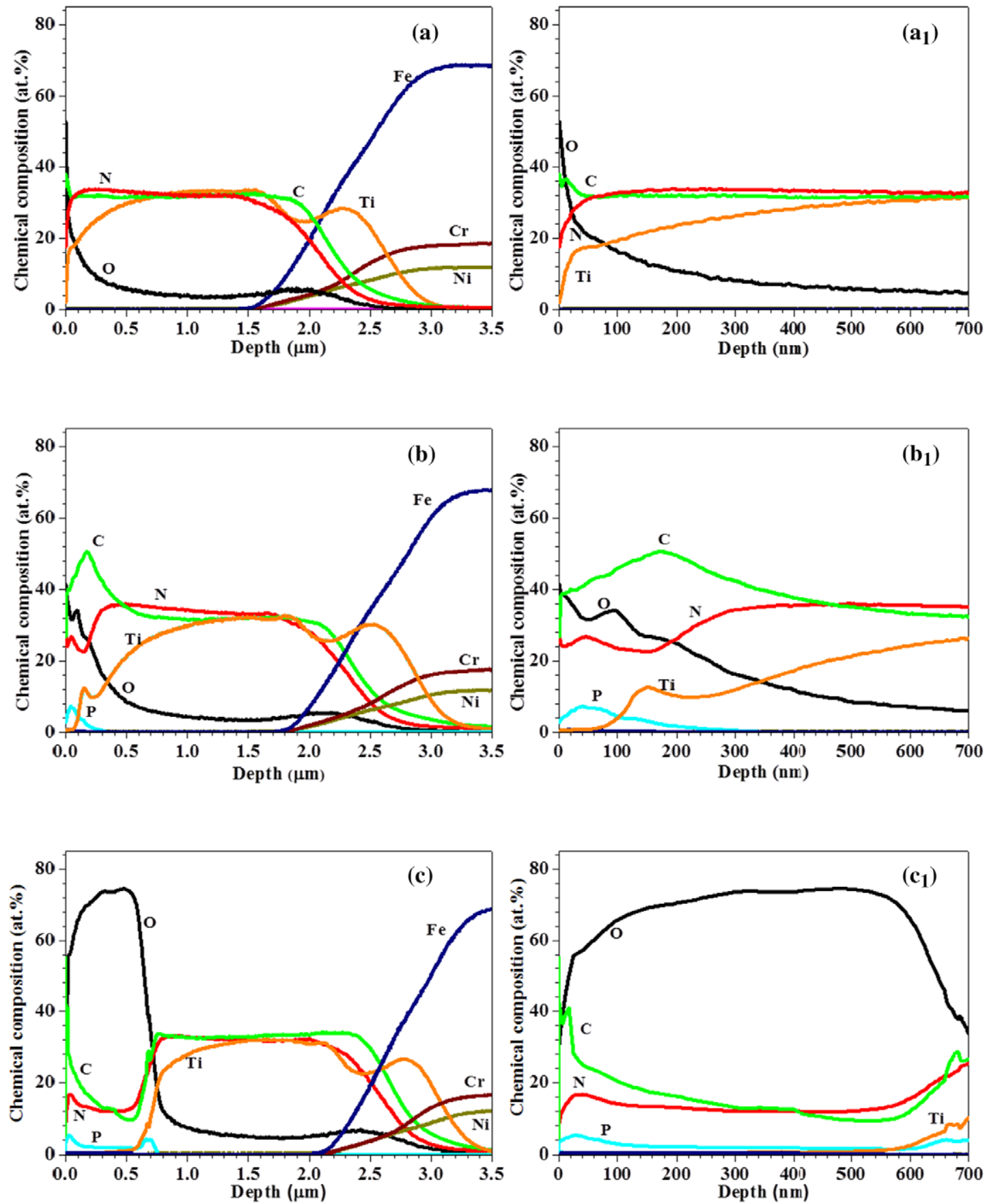

Figure 1. GDOES depth profile of $\mathrm{Ag} / \mathrm{Ti}=0:(a)$ control samples, $(b)$ samples immersed for $24 \mathrm{~h}$ in $\mathrm{TSB}$ and $(c)$ samples immersed for $24 \mathrm{~h}$ in DMEM. $(a),(b)$ and $(c)$ represent the extended depth profiles up to $3.5 \mu \mathrm{m}$ and $\left(a_{1}\right),\left(b_{1}\right)$ and $\left(c_{1}\right)$ represent the depth profiles near the surface $(<700 \mathrm{~nm})$.

X-ray photoelectron spectroscopy (XPS) was carried out to analyse the chemical bonds of the compounds on the coating surface, and also after the treatment of coatings. The tests were performed using a hemispherical analyser (SPECS EA10 Plus) and $\mathrm{Al} \mathrm{K} \alpha$ radiation as the exciting source at a constant power of $300 \mathrm{~W}$. The pass energy was $15 \mathrm{eV}$ giving a constant resolution of $0.9 \mathrm{eV}$. The $\mathrm{Ag} 3 \mathrm{~d}_{5 / 2}$ line at $367.9 \mathrm{eV}$ was used to calibrate the binding energies (BE). All samples (those that were in contact or not with the culture media) were not sputtercleaned in order to obtain the effect of the electrolytes on the surface. The curve-fitting analysis of all core levels was performed using a Gaussian curve-fitting function, in CasaXPS software.

\section{Results and discussion}

\subsection{Chemical composition}

The chemical composition, thickness and some experimental details of two different $\mathrm{Ag} / \mathrm{Ti}$ atomic ratios are summarized in table 1. The carbon and nitrogen content do not vary significantly. The Ti content decreased from 37 to 32 at $\%$ 

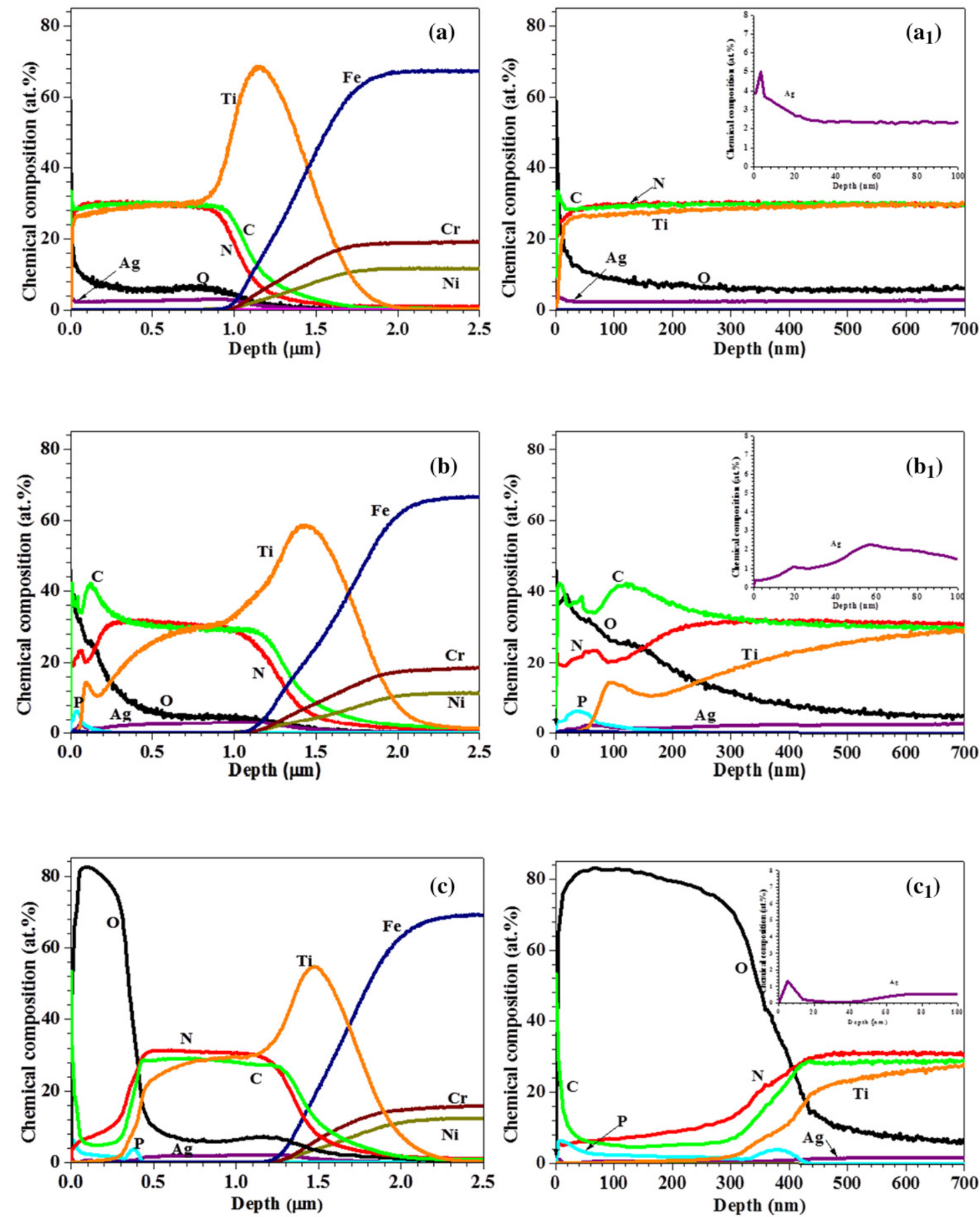

Figure 2. GDOES depth profile of $\mathrm{Ag} / \mathrm{Ti}=0.20$ : $(a)$ control samples, $(b)$ samples immersed for $24 \mathrm{~h}$ in $\mathrm{TSB}$ and $(c)$ samples immersed for $24 \mathrm{~h}$ in DMEM. $(a),(b)$ and $(c)$ represent the extended depth profiles up to $2.5 \mu \mathrm{m}$ and $\left(a_{1}\right),\left(b_{1}\right)$ and $\left(c_{1}\right)$ represent the depth profiles near the surface $(<700 \mathrm{~nm})$ and the insets represent a higher detail on the $\mathrm{Ag}$ profile.

being mainly substituted by $\mathrm{Ag}$, with an increasing content from 0 to 6 at $\%$.

\subsection{Depth profile characterization}

GDOES profiles of coatings with $\mathrm{Ag} / \mathrm{Ti}$ atomic ratios of 0 and 0.20 before and after immersion in the culture media are presented in figures 1 and 2, respectively.

The spectra of control samples (without media immersion) without and with silver (figures $1(a)$ and 2(a), respectively) present an oxidation in the top surface $(<20 \mathrm{~nm})$, with the oxygen content decreasing progressively within the bulk coating. This effect is more noticeable in figures $1\left(a_{1}\right)$ and $2\left(a_{1}\right)$, where the first $700 \mathrm{~nm}$ of the samples are zoomed. The oxidation on the surface is probably due to some contamination by exposure to the environment. The oxygen inside the coating probably stems from the residual oxygen in the deposition chamber during the production, as well as from the small amount that is due to natural oxidation from the target surface, constituted by metals, which occurs 
(a) $\quad 1000 \quad 1500 \quad 2000 \quad 2500 \quad 3000 \quad 3500$

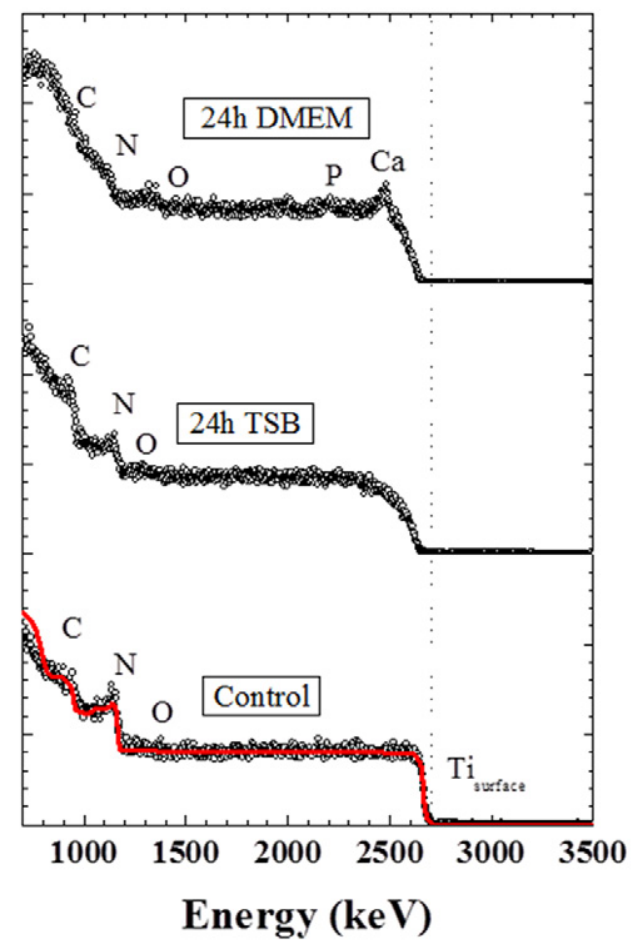

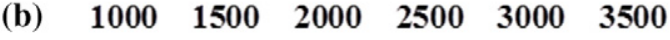

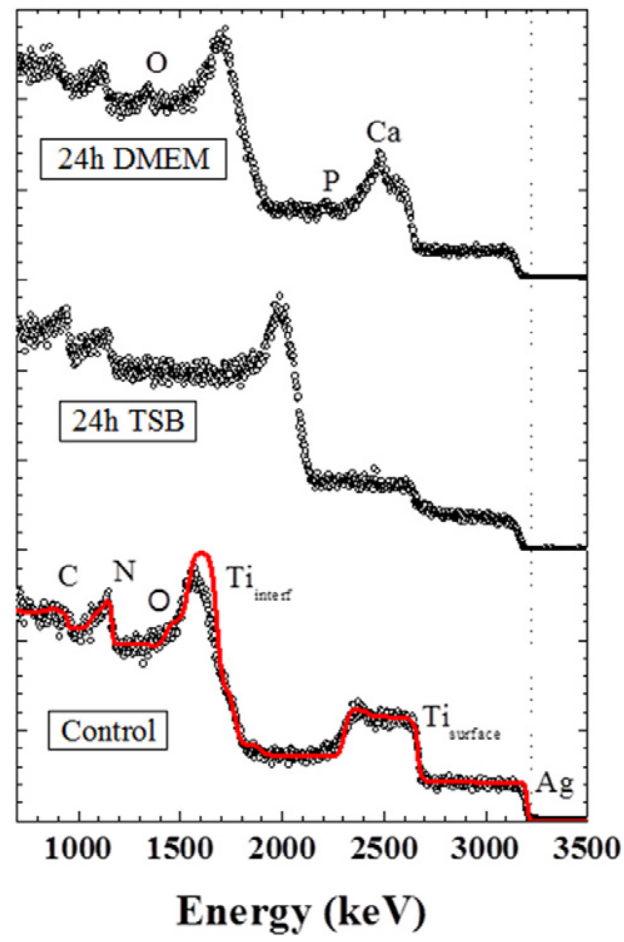

Figure 3. RBS spectra of samples with $(a) \mathrm{Ag} / \mathrm{Ti}=0$ and $(b) \mathrm{Ag} / \mathrm{Ti}=0.20$ immersed in DMEM (top), in TSB (middle) and control (bottom).

unavoidably when the samples are in contact with the moisture in the environment [28]. In these figures, the homogeneous elemental composition within the bulk deposited coating (thickness above $500 \mathrm{~nm}$ and $20 \mathrm{~nm}$ for $\mathrm{Ag} / \mathrm{Ti}=0$ and $\mathrm{Ag} / \mathrm{Ti}=0.20$, respectively) can be observed until the $\mathrm{Ti}$ interlayer is reached. The chemical composition of these samples corroborates with that obtained by EPMA.

GDOES profiles for samples with $\mathrm{Ag} / \mathrm{Ti}$ atomic ratios of 0 and 0.20 which were in contact with TSB for $24 \mathrm{~h}$ (figures $1(b)$ and $2(b)$ ), respectively, show the presence of phosphorus on the surface. However, this presence was not confirmed either by RBS or by XPS, as will be discussed later. Figures $1\left(b_{1}\right)$ and $2\left(b_{1}\right)$ show a high heterogeneity in the chemical composition on the first $700 \mathrm{~nm}$ of both samples. An increase in the carbon content can be seen, reaching the maximum concentration at approximately $170 \mathrm{~nm}$ and $120 \mathrm{~nm}$ in depth, for the samples without and with silver, respectively. Moreover, it should be noted that for both samples there is a very thin surface layer (with a thickness of $70 \mathrm{~nm}$ and $50 \mathrm{~nm}$ for samples with $\mathrm{Ag} / \mathrm{Ti}=0$ and $\mathrm{Ag} / \mathrm{Ti}=0.20$, respectively) without detection of titanium and with a significant decrease in the silver content (inset of figure $\left.2\left(b_{1}\right)\right)$. This layer may indicate the presence of organic compounds on top of the deposited coatings, since contributions of only carbon, nitrogen and oxygen (and, to a smaller extent, phosphorus) are observed, and these elements are the principal constituents of proteins, important components of TSB.

Finally, GDOES profiles of the samples subjected to immersion in DMEM (figures 1(c) and 2(c)) exhibit a wide oxidized surface of about $600 \mathrm{~nm}$ and $400 \mathrm{~nm}$ thickness for the coatings without and with silver, respectively. In this same coating thickness, the emergence of phosphorus can be seen, and in this case, its presence was confirmed by RBS and XPS, as will be discussed later. Underneath the oxidized layer it can be observed that the film remains quite homogeneous, showing the same behaviour found in the control samples.

Figure 3 shows RBS spectra for coatings with $\mathrm{Ag} / \mathrm{Ti}$ atomic ratio of $(a) 0$ and $(b) 0.20$ before (control samples) and after $24 \mathrm{~h}$ of immersion in both culture media (TSB and DMEM).

RBS results (figure 3) confirm the presence of a surface layer on top of the Ag-TiCN coatings for both samples, in agreement with GDOES observations (see figures 1 and 2). The surface Ti signal for the control samples with $\mathrm{Ag} / \mathrm{Ti}=0$ and $\mathrm{Ag} / \mathrm{Ti}=0.20$ sharply appears at an energy of $2660 \mathrm{keV}$ in the RBS spectra of figures 3( $a$ ) and $(b)$ (bottom), respectively. However, for both $\mathrm{Ag} / \mathrm{Ti}$ ratios, after $24 \mathrm{~h}$ of immersion in TSB or DMEM, the titanium signals appear slightly shifted towards lower energy, while the signals of $\mathrm{C}, \mathrm{N}$ and $\mathrm{O}$ remain at their original energies. This is an indication of the deposition of a $\mathrm{C}-\mathrm{N}-\mathrm{O}-$ based coating on the control TiCN film. The decrease in the energy of the titanium signal is due to the loss of energy of $\mathrm{He}^{+}$ions within this top layer until reaching the buried titanium. In a similar way, the surface Ag signal for the $\mathrm{Ag} / \mathrm{Ti}=0.20$ samples immersed in TSB and DMEM appears shifted towards energies lower than $3190 \mathrm{keV}$ (energy of the Ag surface for the control sample) in the RBS spectra of figure $3(b)$. In addition, for the samples immersed in DMEM, there is evidence in the RBS spectra of the presence of two new surface elements (phosphorus and calcium), which are 

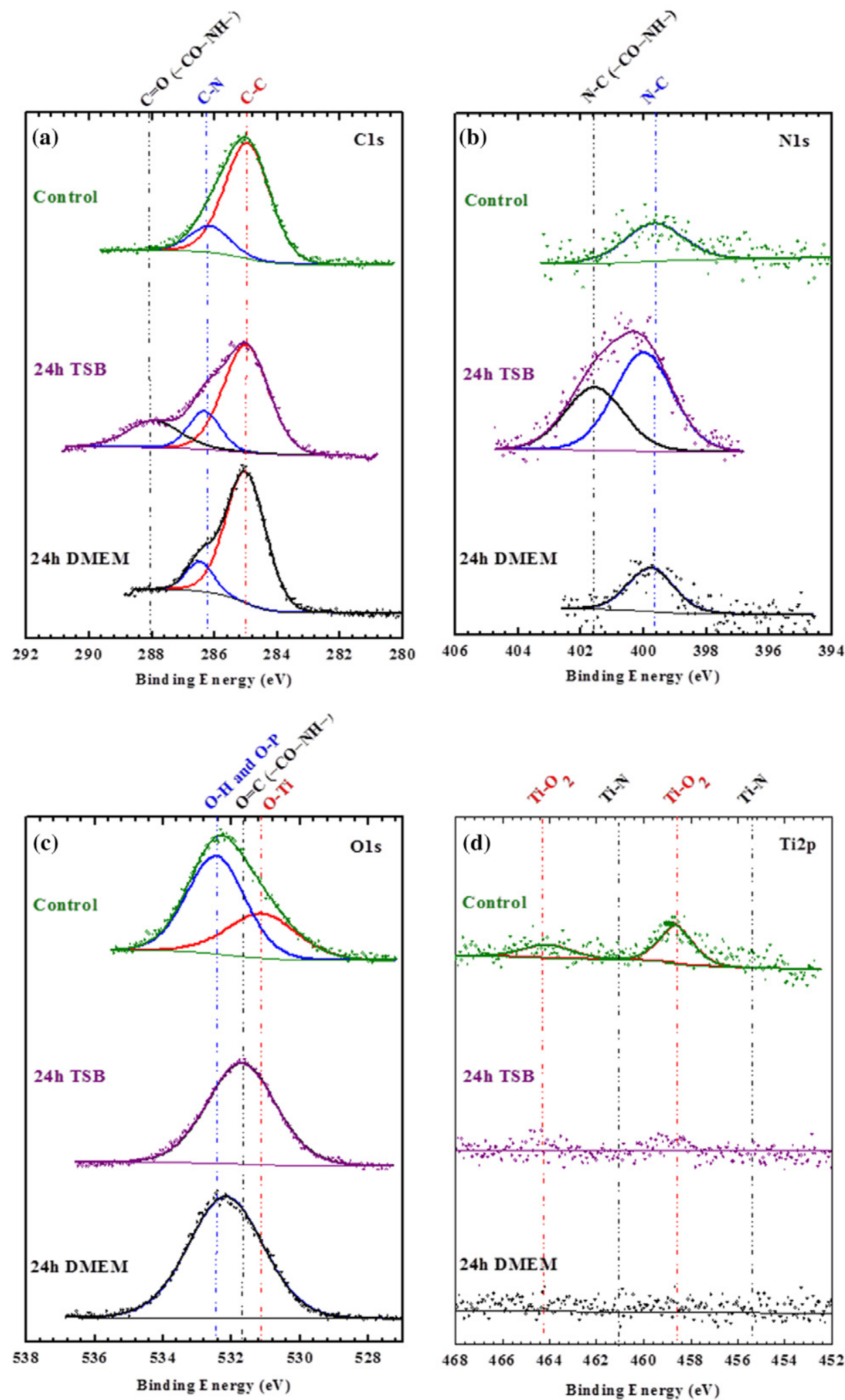

Figure 4. XPS spectra of $(a) \mathrm{C} 1 \mathrm{~s},(b) \mathrm{N} 1 \mathrm{~s},(c) \mathrm{O} 1 \mathrm{~s}$ and $(d)$ Ti $2 \mathrm{p}$ core levels of $\mathrm{Ag} / \mathrm{Ti}=0.20$ in control samples (top), and samples exposed for $24 \mathrm{~h}$ in TSB (middle) and in DMEM (bottom).

the main constituents of the DMEM media. Phosphorus was already detected by GDOES (see figures 1 and 2) but as the GDOES setup was not equipped with a photodetector for the calcium wavelength it was not possible to detect it by this method.

\subsection{Chemical bonding analysis by XPS}

Further information on the chemical bonding of the samples in contact with the culture media was obtained using XPS. The analysis was performed on both samples, with and without 

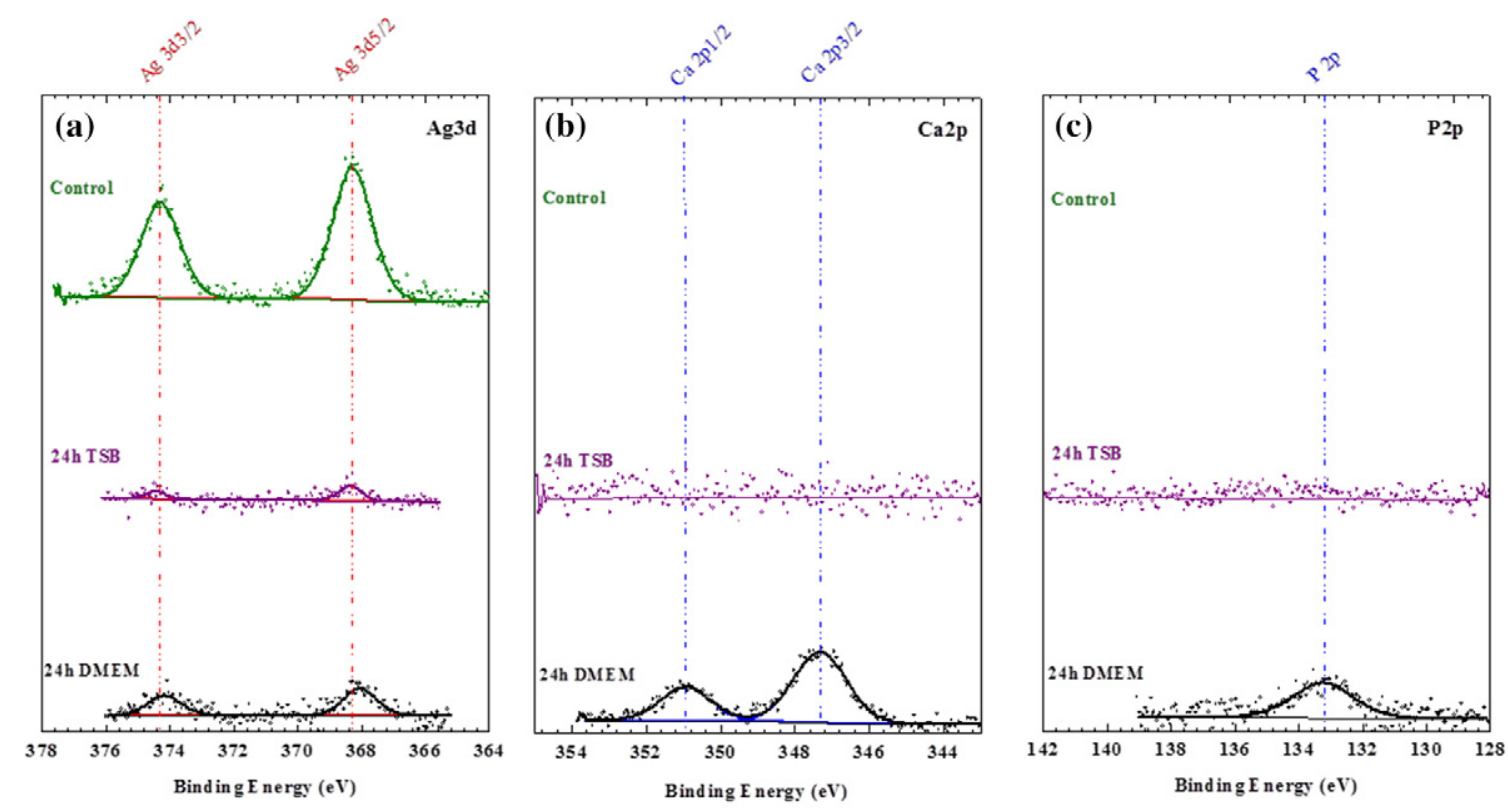

Figure 5. XPS spectra of $(a) \mathrm{Ag} 3 \mathrm{~d},(b) \mathrm{Ca} 2 \mathrm{p}$ and $(c) \mathrm{P} 2 \mathrm{p}$ core levels of $\mathrm{Ag} / \mathrm{Ti}=0.20$ in control samples (top), and samples exposed for $24 \mathrm{~h}$ in TSB (middle) and in DMEM (bottom).

silver. Since both results are very similar, only the results of the sample with silver are presented and discussed.

The effect of BE shift due to charging effects of the samples upon x-ray irradiation was corrected, and all XPS energies refer to that of $\mathrm{C} 1 \mathrm{~s}$ band at $285.0 \mathrm{eV}$. In order to relate the chemical changes in the sample surface to the antibacterial effect in the coating, the $\mathrm{C} 1 \mathrm{~s}, \mathrm{~N} 1 \mathrm{~s}, \mathrm{O} 1 \mathrm{~s}$ and $\mathrm{Ti}$ $2 p$ XPS bands are represented in figure 4 , after BE correction of the control sample, as well as, of the samples immersed in TSB and DMEM. As can be seen in figure 4(a), the C1s band, of the sample immersed in TSB, shows three contributions at $285.0 \mathrm{eV}, 286.4 \mathrm{eV}$ and $288.1 \mathrm{eV}$, respectively. The $\mathrm{C} 1 \mathrm{~s}$ band at $285.0 \mathrm{eV}$ is assigned to $\mathrm{C}-\mathrm{C}$ bonds related to the amorphous carbon phase, in good agreement with Raman spectroscopy results previously published [25].

The band at $286.4 \mathrm{eV}$ is attributed to $\mathrm{C}-\mathrm{N}$ bonds in a $\mathrm{CN}$ amorphous phase. This interpretation is supported by the presence of a contribution at around $400 \mathrm{eV}$ within the $\mathrm{N}$ 1s band (see figure $4(b)$ [29-32]). The peak at $288.1 \mathrm{eV}$ is observed only in the samples treated with TSB and should be assigned to $\mathrm{C}=\mathrm{O}$. The counterpart is also observed in the $\mathrm{O} 1 \mathrm{~s}$ band at around $531.7 \mathrm{eV}$. The carboxylic group points to the presence of organic species, which were also identified in other studies [31-34], and is confirmed by the GDOES analysis. In addition to that, the $\mathrm{N} 1 \mathrm{~s}$ band for the sample treated with TSB shows another contribution at $\sim 401.5 \mathrm{eV}$, which should be attributed to $\mathrm{C}-\mathrm{N}$ bonds in the organic matrix $[33,35]$. This organic material, being adsorbed on the coating's surface, prevents silver diffusion to the surface and consequently its ion release. For the samples either sterilized or immersed in DMEM, the $\mathrm{O} 1 \mathrm{~s}$ band shows a peak at $\sim 532.3 \mathrm{eV}$ that could be attributed either to $\mathrm{O}-\mathrm{H}$ or $\mathrm{O}-\mathrm{P}$ bonds, respectively. The presence of $\mathrm{O}-\mathrm{H}$ bonds in the control sample is also observed with GDOES and is attributed to surface contamination by environmental components. However, as will be discussed later, the presence of $\mathrm{O}-\mathrm{P}$ bonds in the samples treated with DMEM is attributed to the formation of a phosphate thin layer on the surface. The peaks at $531.1 \mathrm{eV}$ for the $\mathrm{O} 1 \mathrm{~s}$ band and that at $458.4 \mathrm{eV}$ for the $\mathrm{Ti} 2 \mathrm{p}_{3 / 2}$ band (see figures $4(c)$ and $(d))$ in the control sample are attributed to the formation to oxygen bonded to titanium in good agreement with previously published results [25]. It is worth noting that the Ti contribution disappears upon immersion of the samples in the culture media. This is consistent with GDOES and RBS results, which also show the absence of Ti on the coating surface. For the sample immersed in TSB, the explanation of this behaviour should be found in the formation of a film of proteins on the surface, from TSB constituent, while for the sample immersed in DMEM, it is attributed to the formation of a thin calcium phosphate layer.

Figure 5 shows the $\mathrm{Ag} 3 \mathrm{~d}(a), \mathrm{Ca} 2 \mathrm{p}(b)$ and $\mathrm{P} 2 \mathrm{p}$ (c) bands measured for the control sample, the sample treated with TSB, and for that treated with DMEM, respectively. The control sample shows an $\mathrm{Ag} 3 \mathrm{~d}$ doublet with the $\mathrm{Ag}$ $3 \mathrm{~d}_{5 / 2}$ peak at $367.8 \mathrm{eV}$, which is attributed to $\mathrm{Ag}-\mathrm{Ag}$ metallic bonds [25], therefore indicating the presence of silver on the coating surface. As can be observed, the intensity of the Ag signal decreases with the immersion of the samples in the culture media, the decrease being more evident for the sample treated with TSB. As pointed out before, these outcomes are in agreement with GDOES and RBS results. The hypothesis formulated earlier about the possible formation of $\mathrm{AgCl}$ was thus ruled out since this peak is not detected. It should be indicated that similar samples, with different chemical compositions, immersed in a simulated body fluid with bovine serum albumin, showed, in a similar way, the formation of a layer of adsorbed proteins on the surface coatings to a depth of $500 \mathrm{~nm}$ [26]. Figure 5 also shows, for the sample immersed in DMEM, a Ca $2 p$ doublet with the $\mathrm{Ca} 2 \mathrm{p}_{3 / 2}$ peak at $347.3 \mathrm{eV}$ and a broad band P $2 \mathrm{p}$ (the doublet is unresolved) at $133.3 \mathrm{eV}$, 
already detected in RBS analysis [36]. These peaks can indeed suggest the presence of a calcium phosphate thin film on the coating surface that may be preventing or reducing the diffusion of silver to the surface and therefore its ionization.

\section{Conclusion}

GDOES, RBS and XPS analyses were carried out on coatings before and after immersion in different culture media in order to find a possible justification for the antibacterial inactivity of these coatings.

All results obtained by these techniques suggest that the modification of the surface caused by exposure of the sample to the culture media can be originated from the formation of a layer of proteins in TSB and calcium phosphate in DMEM. Moreover, this layer seems to justify the absence, or low levels, of silver ionization, which is related to the absence of the antibacterial effect found in these samples [18].

\section{Acknowledgments}

IC acknowledges the financial support of FCT—Fundação para a Ciência e a Tecnologia through the grant SFRH/BD/67022/ 2009. REG acknowledges support from Ramon y Cajal programme (RyC2007-0026). This research is sponsored by FEDER funds through the program COMPETE-Programa Operacional Factores de Competitividade and by national funds through FCT-Fundação para a Ciência e a Tecnologia in the framework of the Strategic Projects PESTC/FIS/UI607/2011, PEST-C/EME/UI0285/2011, PTDC/ CTM/102853/2008.

The authors thank the FCT Strategic Project PEstOE/EQB/LA0023/2013 and the Project'BioHealth-Biotechnology and Bioengineering approaches to improve health quality', Ref. NORTE-07-0124-FEDER-000027, co-funded by the Programa Operacional Regional do Norte (ON.2-O Novo Norte), QREN, FEDER. The authors also thank the project 'Consolidating Research Expertise and Resources on Cellular and Molecular Biotechnology at CEB/IBB', Ref. FCOMP-01-0124-FEDER-027462.

\section{References}

[1] Batory D, Reczulska M C, Kolodziejczyk L and Szymanski W 2013 Gradient titanium and silver based carbon coatings deposited on AISI316L Appl. Surf. Sci. 275 303-10

[2] Kannan S, Balamurugan A and Rajeswari S 2003 Hydroxyapatite coatings on sulfuric acid treated type $316 \mathrm{~L}$ SS and its electrochemical behaviour in Ringer's solution Mater. Lett. 57 2382-9

[3] Antunes R A, Rodas A C D, Lima N B, Higa O Z and Costa I 2010 Study of the corrosion resistance and in vitro biocompatibility of PVD TiCN-coated AISI 316L austenitic stainless steel for orthopedic applications Surf. Coat. Technol. 205 2074-81

[4] Valero Vidal C and Igual Muñoz A 2008 Electrochemical characterisation of biomedical alloys for surgical implants in simulated body fluids Corros. Sci. 50 1954-61
[5] Sánchez-López J C, Abad M D, Carvalho I, Escobar Galindo R, Benito N, Ribeiro S, Henriques M, Cavaleiro A and Carvalho S 2012 Influence of silver content on the tribomechanical behavior on $\mathrm{Ag}-\mathrm{TiCN}$ bioactive coatings Surf. Coat. Technol. 206 2192-8

[6] Martínez-Martínez D, Sánchez-López J C, Rojas T C, Fernández A, Eaton P and Belin M 2005 Structural and microtribological studies of $\mathrm{Ti}-\mathrm{C}-\mathrm{N}$ based nanocomposite coatings prepared by reactive sputtering Thin Solid Films 472 64-70

[7] Serro A P, Completo C, Colaço R, dos Santos F, da Silva C L, Cabral J M S, Araújo H, Pires E and Saramago B 2009 A comparative study of titanium nitrides, TiN, TiNbN and TiCN, as coatings for biomedical applications Surf. Coat. Technol. 203 3701-7

[8] Feng H-P, Hsu C-H, Lu J-K and Shy Y-H 2003 Effects of PVD sputtered coatings on the corrosion resistance of AISI 304 stainless steel Mater. Sci. Eng. A 347 123-9

[9] Chekan N M, Beliauski N M, Akulich V V, Pozdniak L V, Sergeeva E K, Chernov A N, Kazbanov V V and Kulchitsky V A 2009 Biological activity of silver-doped DLC films Diamond Relat. Mater. 18 1006-9

[10] Chen W, Liu Y, Courtney H S, Bettenga M, Agrawal C M, Bumgardner J D and Ong J L 2006 In vitro anti-bacterial and biological properties of magnetron co-sputtered silver-containing hydroxyapatite coating Biomaterials 27 5512-7

[11] Ewald A, Hösel D, Patel S, Grover L M, Barralet J E and Gbureck U 2011 Silver-doped calcium phosphate cements with antimicrobial activity Acta Biomater. 7 4064-70

[12] Fielding G A, Roy M, Bandyopadhyay A and Bose S 2012 Antibacterial and biological characteristics of silver containing and strontium doped plasma sprayed hydroxyapatite coatings Acta Biomater. 8 3144-52

[13] Huang H-L, Chang Y-Y, Lai M-C, Lin C-R, Lai C-H and Shieh T-M 2010 Antibacterial TaN-Ag coatings on titanium dental implants Surf. Coat. Technol. 205 1636-41

[14] Jamuna-Thevi K, Bakar S A, Ibrahim S, Shahab N and Toff M R M 2011 Quantification of silver ion release, in vitro cytotoxicity and antibacterial properties of nanostuctured $\mathrm{Ag}$ doped $\mathrm{TiO}_{2}$ coatings on stainless steel deposited by RF magnetron sputtering Vacuum 86 235-41

[15] Hsieh J H, Tseng C C, Chang Y K, Chang S Y and Wu W 2008 Antibacterial behavior of TaN-Ag nanocomposite thin films with and without annealing Surf. Coat. Technol. 202 5586-9

[16] Akhavan O and Ghaderi E 2009 Capping antibacterial Ag nanorods aligned on $\mathrm{Ti}$ interlayer by mesoporous $\mathrm{TiO}_{2}$ layer Surf. Coat. Technol. 203 3123-8

[17] Sant S B, Gill K S and Burrell R E 2007 Nanostructure, dissolution and morphology characteristics of microcidal silver films deposited by magnetron sputtering Acta Biomater. 3 341-50

[18] Carvalho I, Henriques M, Oliveira J C, Almeida Alves C F, Piedade A P and Carvalho S 2013 Influence of surface features on the adhesion of Staphylococcus epidermidis to Ag-TiCN thin films Sci. Technol. Adv. Mater. 14035009

[19] Chen W, Oh S, Ong A P, Oh N, Liu Y, Courtney H S, Appleford M and Ong J L 2007 Antibacterial and osteogenic properties of silver-containing hydroxyapatite coatings produced using a sol gel process J. Biomed. Mater. Res. A 82 899-906

[20] Ewald A, Glückermann S K, Thull R and Gbureck U 2006 Antimicrobial titanium/silver PVD coatings on titanium Biomed. Eng. Online 522

[21] Kumar R and Münstedt H 2005 Silver ion release from antimicrobial polyamide/silver composites Biomaterials 26 2081-8 
[22] Lan W-C, Ou S-F, Lin M-H, Ou K-L and Tsai M-Y 2013 Development of silver-containing diamond-like carbon for biomedical applications: I. Microstructure characteristics, mechanical properties and antibacterial mechanisms Ceram. Int. 39 4099-104

[23] Trujillo N A, Oldinski R A, Ma H, Bryers J D, Williams J D and Popat K C 2012 Antibacterial effects of silver-doped hydroxyapatite thin films sputter deposited on titanium Mater. Sci. Eng. C 32 2135-44

[24] Chernousova S and Epple M 2013 Silver as antibacterial agent: ion, nanoparticle, and metal. Angew. Chem. Int. Edn Engl. 52 1636-53

[25] Manninen N K, Galindo R E, Benito N, Figueiredo N M, Cavaleiro A, Palacio C and Carvalho S 2011 Ag-Ti (C, $\mathrm{N}$ )-based coatings for biomedical applications: influence of silver content on the structural properties J. Phys. D: Appl. Phys. 44375501

[26] Alves C F A, Oliveira F, Carvalho I, Piedade A P and Carvalho S 2014 Influence of albumin on the tribological behavior of $\mathrm{Ag}-\mathrm{Ti}(\mathrm{C}, \mathrm{N})$ thin films for orthopedic implants Mater. Sci. Eng. C 34 22-8

[27] Escobar Galindo R, Manninen N K, Palacio C and Carvalho S 2013 Advanced surface characterization of silver nanocluster segregation in $\mathrm{Ag}-\mathrm{TiCN}$ bioactive coatings by RBS, GDOES, and ARXPS Anal. Bioanal. Chem. 405 6259-69

[28] Calderon V S, Galindo R E, Oliveira J C, Cavaleiro A and Carvalho S $2013 \mathrm{Ag}^{+}$release and corrosion behavior of zirconium carbonitride coatings with silver nanoparticles for biomedical devices Surf. Coat. Technol. 222 104-11
[29] Palacio C, Gómez-Aleixandre C, Díaz D and García M 1997 Carbon nitride thin films formation by $\mathrm{N}_{2}^{+}$ion implantation Vacuum 48 709-13

[30] Riedo E, Comin F, Chevrier J and Bonnot A M 2000 Composition and chemical bonding of pulsed laser deposited carbon nitride thin films J. Appl. Phys. 884365

[31] Serro A, Gispert M, Martins M, Brogueira P, Colaço R and Saramago B 2006 Adsorption of albumin on prosthetic materials: implication for tribological behavior J. Biomed. Mater. Res. A 78 581-9

[32] Vanea E, Magyari K and Simon V 2010 Protein attachment on aluminosilicates surface studied by XPS and FTIR spectroscopy J. Optoelectron. Adv. Mater. 12 1206-12

[33] Advincula M, Fan X, Lemons J and Advincula R 2005 Surface modification of surface sol-gel derived titanium oxide films by self-assembled monolayers (SAMs) and non-specific protein adsorption studies Colloids Surf. B 42 29-43

[34] Lebugle A, Subirade M and Gueguen J 1995 Structural characteristics of a globular protein investigated by $\mathrm{x}$-ray photoelectron spectroscopy: comparison between a legumin film and a powdered legumin Biochim. Biophys. Acta-Protein Struct. Mol. Enzymol. 1248 107-14

[35] Moulder J F, Stickle W F, Sobol P E and Bomben K D 1992 Handbook of X-Ray Photoelectron Spectroscopy ed J Chastain (Eden Prairie, MN: Perkin-Elmer Corporation)

[36] Ciobanu C S, Iconaru S L, Pasuk I, Vasile B S, Lupu A R, Hermenean A, Dinischiotu A and Predoi D 2013 Structural properties of silver doped hydroxyapatite and their biocompatibility Mater. Sci. Eng. C 33 1395-402 